\title{
The Response of Pre-Service Teachers to a Compulsory Research Project
}

\author{
Kylie Shaw \\ Allyson Holbrook \\ Jill Scevak \\ Sid Bourke \\ SORTI, The University of Newcastle
}

\begin{abstract}
This paper draws on 159 survey responses of fourth year Education students as they embark on a research project based in their internship school. The project explores predisposition to research and the level of preparedness to undertake a research project. The students who met most frequently with their supervisor and showed higher research self-efficacy were also most likely to want to undertake postgraduate study and reacted positively to good personal support and a feeling of belonging to a research "community". Many felt they were "unconnected" to a learning community, and specifically to their supervisor. They were generally positive about their ability to do the tasks, such as finding and writing up literature, even though they were concerned about managing the overall commitment. Despite this they were optimistic about completion. Only 5\% were sure they would undertake postgraduate study in the future, and 65\% were sure they would not do so. In an environment where there is commitment to promoting research skills consistent with the needs of a knowledge society and drawing on evidence to inform practice, the findings not only raise the question of how best to support and give meaning to early research endeavours of preservice teachers, but also highlights the challenge of achieving this against a high level of disinterest in further tertiary study.
\end{abstract}

\section{Introduction}

Higher education accounts for more than one quarter of all research and development expenditure in Australia (Burgio-Ficca, 2001) and a large proportion of the research output is generated by research students. This is particularly the case in Education where the numbers undertaking research degrees grew rapidly throughout the 1990s. 
While many education practitioners return to higher education to upgrade their skills and knowledge in a professional capacity through coursework or research, most do not. In education there is a continual undercurrent of questioning about the relevance and quality of educational research produced in universities (Holbrook, et al., 2000, p. 25) and on the whole the prevailing impression in the 1990s was that of an "awful" mismatch (Kaestle, 1993). However, there is now a considerable body of literature that shows how teachers draw on research information and initiate, and take a partnership role in projects (McMeniman, Cumming, Wilson, Stevenson, \& Sim, 2000). Clearly, personal engagement and practitioners determining what "counts" in school contexts is the key (Figgis, Zubrick, Butorac, \& Alderson, 2000). Moreover, the movement toward "evidence-based practice" has gained momentum and is stressed in the context of professional excellence, school performance and systemic reform (James, 2006).

Research skills are generally seen to be essential for successful operation in a global knowledge economy (Davis, Evans, \& Hickey, 2006) and to sustain lifelong learning and professional development (Waite \& Davis, 2006). Hence it is hardly surprising that the acquisition of such skills is deemed to be a valuable outcome of tertiary education, not least in teacher education. While academics argue as a rule that a general grounding in research skills and understandings at the undergraduate level will result in receptiveness to research and informed consumption of new information that carries through into professional life (Reis-Jorge, 2005), there are some who caution that the development of research skills works best for those motivated toward research (Diezmann, 2005) and not necessarily for all pre-service teachers. This is an important issue that needs to be further explored.

There also tends to be an assumption that undergraduates by virtue of doing a degree will develop an alignment to the university research community, but Robertson and Blacker (2006) show how this is not necessarily the case. They found in a crossdisciplinary study of 34 students in one institution that some students have an early sense of proximity to, and participation in, a research community, while for others research remains a remote phenomenon throughout their undergraduate years. This has implications for future enrolments, research capacity, postgraduate attrition, and knowledge "use". Given the interest internationally in promoting postgraduate study and research skills it is surprising how little attention has been paid to research experience at undergraduate level (Reis-Jorge, 2005; Holmberg, 2006).

In teaching much has been made of the theory-practice gap over the years, and there are many courses that now seek to secure a cultural shift through providing direct involvement in research in undergraduate courses, but as yet the impact has not been adequately tested. We anticipate the results will be positive because we know that good teachers draw on research-based evidence to upgrade their working knowledge, but 
what of teachers as a group? How fragile is the "connection" between exposure to, and engagement in, research activity at undergraduate level and future interest in research in Education? How do pre-service teachers respond to research experience, particularly the experience of undertaking a significant mandatory research project toward the later stages of their undergraduate degree? To what extent will this experience impact on their perception of the usefulness of research, their engagement with professional and academic communities, and intention to continue on to postgraduate study?

It is the last point that is the main focus of this study. We followed pre-service teachers through the early stages of a school based research project, and then looked at their projections about, and motivations for, involvement in future postgraduate study. It explores their readiness to engage in research and the importance of their initial experiences in setting up expectations. The paper addresses the following questions:

1. How motivated and confident are pre-service teachers about doing research?

2. What is their initial experience of research?

3. How positive are they about the process and the environment?

4. Do they have an interest in undertaking postgraduate study and what factors can contribute to this?

\section{The Approach}

\section{The course}

The Teacher Research Project (TRP) is a 10 credit point course that students in all teaching specialisations within the double degree course are required to complete. The goal is to help students develop:

- An understanding of the nature of educational research and how it relates to educational practice;

- Skill in conducting a review of the literature on a specific educational topic;

- Skill in comprehending, interpreting, evaluating and applying the findings of published research articles and other research reports;

- An understanding of the basic procedures involved in research;

- Professional Practice - the inclination to draw upon research findings when making educational decisions; and,

- Skill in using evaluation research to investigate local educational problems. 
The TRP is undertaken in conjunction with school internship. It is a requirement of the degree that students have 50 days of school based experience in their fourth year. The intern is responsible for up to $2 / 3$ of the colleague teacher's teaching load in their internship school.

In the original design of the double degree structure, students were required to complete a 10 credit point course Project Preparation in order to provide them with the required prior knowledge to complete their own research project. The content of this course included an orientation to educational research, types of educational research, preliminary skills needed for conducting research, locating published research, interpreting and summarizing published research and designing their own research project. Due to competing demands in the double degree curriculum the credit points for the project preparation course were assigned to another area of the curriculum and the content of the course was incorporated into the teacher research project. This move to incorporate two courses into one had significant ramifications for the students' workload in the course (essentially 20 credit points of work were compressed into a 10 credit point course).

In order to minimise the impact of this development on student workload, the students were provided with the opportunity to begin independent preparation for the TRP in the previous semester and administrative arrangements were put in place to make this possible. Students register in a supervisor's group (the average group size is between 10 and 20). All supervisors have a postgraduate qualification and specialist knowledge of the research process. Students choose specific supervisors because they have worked with them in previous courses during their double degree programme or because of their particular research interests (these interests are listed on each staff member's web page). During one of the exam weeks at the end of Semester One students are required to participate in a compressed delivery of the project preparation course. This consists of one 2-hour lecture covering an introduction to the purpose of the project and the supporting resources for the course and another 2-hour lecture on the literature review. Students are then expected to complete required readings on research methods and other aspects of research such as validity and reliability. A blackboard site/Web CT is set up for the students containing information about the requirements of the TRP, preliminary reading and self testing tasks to cover the course content.

After the completion of these tasks, students are required to prepare a one page written proposal for their teacher research project. The proposal includes an outline of the problem/question/hypothesis, theoretical framework, method and the project's educational significance. After preparing the proposal students are required to contact their supervisor to discuss the proposal and refine or modify it. These discussions 
sometimes result in a change of focus for their project or a different question. Students are always encouraged to choose a topic that they are interested in. Some students ask their internship school if there are any research areas that the school would like to address and as a result the student may tap into this (e.g., an evaluation of the school's bullying policy).

Frequency of contact (face-to-face, e-mail, telephone) with supervisors is for the most part student initiated. Some supervisors hold informal group meetings on the scheduled days for the internship course meetings on campus. The opportunities for contact and discussion with the group/individuals and the advisor are limited, because of the workload demands of internship and for many students the additional responsibility of part-time employment. As a result of the many demands on students during this period the opportunity to seek support and develop a supportive network within a collegial research environment in the School of Education is also limited.

After the course, students whose work is considered to be of high quality (awarded a Distinction or High Distinction) are invited to consider postgraduate study informally by their supervisor and officially via a letter of invitation from the Course Co-coordinator

\section{The instrument}

This paper draws on the questionnaire responses of 159 fourth-year Education students at the University of Newcastle as they embarked on a research project during the second semester of their fourth year internship and TRP. It draws on the methodology developed for a larger cross-disciplinary study currently underway. The larger study is looking at the issues of research interest, motivation and confidence in completing research tasks of final year undergraduate and honours students across the fields of Science, Engineering, Health and Social Science as well as Education. The TRP accounts for $12.5 \%$ of credit points of the final year of the Bachelor of Teaching or Bachelor of Education program and is expected to be undertaken in the student's internship school. Students design their own school-based project in conjunction with their academic advisor/supervisor and their supervising teacher(s) at the school.

The 159 respondents represent $49 \%$ of the 326 students enrolled in the course. The students were from nine different specializations in the Education Faculty. The programs included the Bachelor of Education and Bachelor of Teaching double degrees in the areas of Design \& Technology, Early Childhood Studies, Art, Fine Art, Health \& Physical Education, Music, Science, and Social Science. When the distribution of responses was compared to the pattern of specializations for the year the match was close to identical. The largest groups of respondents were from the Bachelor of Teaching/Bachelor of Arts (50\%); Bachelor of Teaching/Bachelor of Health and Physical Education (18\%); and Bachelor of Teaching/Bachelor of Early Childhood 
Studies (14\%) programs. The respondents in each program are generally representative of the fourth-year cohort in that year. The majority of respondents were female (77\%) and aged between 21 and 24 years (79\%).

The questionnaires were distributed to fourth year students in the Professional Preparation lecture in their second semester of study in 2005. At that time most students had completed their research proposal and ethics submission, and were commencing the data collection at their internship school. The lecture provided the only opportunity to access all students once they had commenced their internship. There was no parallel opportunity at the completion of the program because dispersion of students is rapid, and lecturers are under pressure to complete all program elements, none of which involve mass lectures. The survey was completed on a voluntary basis, responses were anonymous and no names were collected. The primary intent was to collect data that captured early phase preparation (literature review, question identification, proposal development, project negotiation), and to obtain a perspective on the positive or negative orientation to the different elements of the process. To achieve the latter a "journey" plot that accommodated projection into the future was incorporated as the final section of the questionnaire. This was completed by $34 \%$ of the students who responded to the questionnaire.

The questionnaire asks for demographic information about the respondent; information about the structure of their program, and details about the research project. It contains items grouped in the areas: research efficacy, research environment, learning motivation and research orientation. The learning motivation, research self-efficacy and research environment areas were developed from existing scales and the literature on undergraduate research student experience. The theoretical background of the areas and scales will be outlined as the results are presented. All three scales have a series of statements where the respondent is asked to indicate on a six-point Likert scale the extent of their agreement with the statement, from Strongly Disagree (1) to Strongly Agree (6). A score of 3.5 on such a scale indicates neither agreement nor disagreement. The fourth area, research orientation, draws on the visualization of the journey.

\section{How Motivated and Confident are Pre-Service Teachers about Research?}

\section{Learning motivation}

Access to the TRP course cohort provides a valuable opportunity to explore how students react to the demands made of them to become independent professional learners in a research and training context. But how motivated were they? 
The motivation section of the questionnaire assesses students' goals and value beliefs for a course, their beliefs about their skills to succeed in a course, and their use of different cognitive and metacognitive strategies. The theoretical framework upon which motivation was explored draws on a social-cognitive view of motivation and learning strategies, and is largely based on the Motivated Strategies and Learning Questionnaire (MSLQ). Within this framework the student is assigned an active role in the learning process and is influenced by their beliefs about learning and their interpretation of the task at hand (Garcia-Duncan \& McKeachie, 2005). Three general types of motivational beliefs are outlined (Pintrich \& Schunk, 1996): self-efficacy beliefs (judgments of one's ability to do the academic task/s), task value beliefs (beliefs about the importance of, interest in, and value of the task) and goal orientations (is the focus on learning the task, grades or extrinsic reasons for doing the task). Motivation is a dynamic and contextually bound concept, that is, students' motivation varies for different courses (e.g., more interest in an elective course as opposed to a mandatory course; more efficacy for an easier course than a difficult course) and strategy selection may vary according to the nature of the task itself (e.g., multiple choice versus essay exams).

Three areas were adapted from the MSLQ for this study - Intrinsic Value, Selfregulation and Cognitive Strategy Use. The scale descriptors and characteristics are shown in Table 1.

\begin{tabular}{|c|c|c|c|c|}
\hline Scale & $\begin{array}{c}\text { Number } \\
\text { of items }\end{array}$ & Example item & Mean (SD) & $\begin{array}{c}\text { Scale } \\
\text { reliability }\end{array}$ \\
\hline Intrinsic Value & 4 & $\begin{array}{c}\text { I think what I am learning in this course is } \\
\text { useful for me to know }\end{array}$ & $4.67(0.7)$ & 0.76 \\
\hline Self Regulation & 5 & $\begin{array}{c}\text { Even when study is dull and uninteresting } \\
\text { I keep studying until I finish }\end{array}$ & $4.28(0.7)$ & 0.65 \\
\hline Cognitive Strategy Use & 4 & $\begin{array}{c}\text { When I am studying for a topic, I try and } \\
\text { make everything fit together }\end{array}$ & $4.49(0.6)$ & 0.58 \\
\hline
\end{tabular}

Table 1: Learning Motivation scale characteristics $(n=152)$

Students were motivated to complete their Teacher Research Project, with all means falling between tend to agree and agree. The agreement was strongest for Intrinsic Value (4.67). Their perceptions of their self regulation and cognitive strategy use were also positive, suggesting that at this stage in the course they were, as a group, determined to see it through and they felt they could meet the intellectual challenges.

\section{Research self efficacy}

Forester, Kahn and Hesson-McInnis (2004) define research self efficacy as confidence in successfully performing tasks associated with conducting research. Research self 
efficacy measures have been found to "predict graduate students' interest in conducting research" (Forester et al., p. 4). They developed four scales based on the work of Bandura on self-efficacy. These have been adapted for undergraduate research and identify students' conceptions and expectations about their research skills. The respondent rates their confidence in their ability to perform research activities through a series of 20 statements. Components include: Conceptualisation; Implementation; Early Tasks; and Presenting the Results.

\begin{tabular}{|c|c|c|c|c|}
\hline Scale & $\begin{array}{c}\text { Number } \\
\text { of items }\end{array}$ & Example item & Mean (SD) & $\begin{array}{c}\text { Scale } \\
\text { reliability }\end{array}$ \\
\hline Conceptualisation & 5 & Brainstorm areas in the literature to read about & $4.17(0.6)$ & 0.83 \\
\hline Implementation & 5 & Generate researchable questions & $4.10(0.8)$ & 0.85 \\
\hline Early Tasks & 5 & Choose appropriate data analysis technique & $3.98(0.8)$ & 0.87 \\
\hline $\begin{array}{c}\text { Presenting the } \\
\text { Results }\end{array}$ & 5 & Interpret and understand statistical printouts & $3.98(0.8)$ & 0.86 \\
\hline
\end{tabular}

Table 2: Research Self Efficacy scale characteristics $(n=147)$

It is evident in Table 2 as it was in Table 1 that the results are positive overall. Most respondents indicated they were more confident with conceptual tasks such as brainstorming ideas for the literature (4.19) and implementation tasks (4.10) such as generating researchable questions. In many cases these are the tasks which had been completed by students at the time of completing the questionnaire. Students tended to be slightly less confident with tasks such as choosing the appropriate data analysis techniques (3.98) and presenting results such as interpreting and understanding statistical printouts (3.98). This may be because they anticipate these tasks will be harder than the ones they have already completed. The type of research training received may also have a bearing on students' confidence in completing particular tasks, as the lecture sessions covered only the early stages of the project leaving the students to conduct their own reading and perhaps seeking the assistance of their supervisor for the later stages such as analysing and presenting results.

\section{Research Environment and the Initial Experience}

It has been shown above that students felt that, by and large, they were prepared for the course. However, were they ready for the essentially independent research experience of setting up their own project and did they feel well-supported? 


\section{Research environment}

Research Environment includes two areas developed from the literature on the experience of undergraduate student researchers. The literature identifies some of the difficulties undergraduate research students' experience such as isolation and time management (Hawes \& Flanagan, 2000). Also outlined are factors which affect the nature of the transitional experience from undergraduate to research higher degrees such as resources available, and support structure provided, and the sense of belonging within the research environment (Johnston \& Broda, 1996; Lovitts, 2005). Lovitts found that factors which contributed to degree completion included the immediate setting in which the student works, the interactions which take place within that setting and the distribution of resources, particularly the availability of experienced supervisors.

The two sets of items reflect both learning community and research support, and consist of a series of 11 statements. Items in the questionnaire such as contact with supervisor; contact with industry or members of profession; whether research involves contact with a research group; and the types of facilities and access to resources required for the respondents' research are also included in the analysis of the research environment.

\begin{tabular}{|c|c|c|c|c|}
\hline Scale & $\begin{array}{c}\text { Number } \\
\text { of items }\end{array}$ & Example item & Mean (SD) & $\begin{array}{c}\text { Scale } \\
\text { reliability }\end{array}$ \\
\hline Research Support & 5 & I have access to adequate library resources & $4.19(0.7)$ & 0.73 \\
\hline Learning Community & 6 & I can talk to lecturers about problems I am experiencing & $3.63(0.8)$ & 0.56 \\
\hline
\end{tabular}

Table 3: Research Environment scale characteristics $(n=152)$

Respondents tended to be positive towards the statements forming the Research Support Scale. They felt that they had a positive research environment, in terms of access to resources, services and networks on campus.

The Academic Learning Community comprises the individuals or groups supporting the TRP students. It embraces academics, professionals and other students. However, as can be seen from Table 3, on average the respondents tended to be neutral with respect to statements forming the Learning Community Scale. They did not feel attached to the faculty or university community, to student associations, nor did they want to explore academic interests, or access the academics in the School to share ideas. These findings align with those of Robertson and Blacker (2006) who found that students may not feel a connection to academic community but, unlike the students they studied, this group was being directly encouraged to think of themselves as part of a broader research and learning community. 
Supervision is an important part of an undergraduate research students' experience (Anderson, 2004; Fitzsimmons, Anderson, McKenzie, \& Chen, 2003). Supervision of the TRP was mainly through an individual supervisor for each student (96\%). There is generally an equal mix of gender of supervisors, with slightly more males (53\%). Most supervisors had a number of students to mentor. Most students felt that they had some or a lot of involvement in the choice of project topic (90\%) and perceived that their supervisor had little or no (48\%), or some (26\%), specific "expertise" in their topic. Respondents indicated that meetings with their supervisor occurred infrequently (less than monthly) and in many cases rarely or not at all (83\%).

Those students who did experience connection with the learning community met more frequently with their supervisor, and were more likely to be involved in a research group as shown in Table 4. However, the correlation coefficients, when significant, were moderate rather than high.

\begin{tabular}{|c|c|c|}
\hline Scale/ltem & $\begin{array}{c}\text { Frequency of meeting } \\
\text { supervisor/s }\end{array}$ & $\begin{array}{c}\text { Member of a } \\
\text { research group }\end{array}$ \\
\hline Learning Community scale & $0.21^{*}$ & $0.22^{*}$ \\
\hline Research Support scale & $\mathrm{NS}$ & $0.17^{*}$ \\
\hline \multicolumn{2}{|c|}{${ }^{*}$ Correlations significant at the 0.05 level } \\
\hline Intention to Continue to Postgraduate study item & $0.17^{*}$ & $\mathrm{NS}$ \\
\hline \\
Table 4: Significant correlations with Frequency of meeting \\
supervisor/s and Membership of a research group
\end{tabular}

Those who met more often with their supervisor were more likely to feel they were members of a learning community and more likely to intend to continue on to postgraduate study. Those who were members of a research group were more likely to feel they were members of a learning community and were more positive about the support being given by their university for their research. Fitzsimmons et al. (2003) and more recently Anderson (2004) found that the small group approach to supervision at The University of Wollongong provided high levels of support and alleviated feelings of isolation, which supports the findings in this study.

The experience of an undergraduate research project may be enhanced by developing research groups with key supervisors, and setting up regular meetings with the group. It is suggested that this would have a positive effect on the sense of belonging to the academic learning community. 


\section{Contact with the profession}

The professional community is made up of students' peers and members of the profession, in this case teachers in schools. It is anticipated that pre-service teachers should be developing a sense of connectedness to their professional community, developing relationships with teachers through practicum experiences in schools. In addition they are developing working relationships with their peers through undergraduate group work which is also emphasized throughout their degree. These peers will continue on to be professional colleagues as they continue into the workforce. Results indicate that those students who already had sustained contact with their profession within a school environment whilst developing their project had more confidence in completing research tasks in the implementation phase, and felt more a part of the learning community (Table 5).

\begin{tabular}{|c|c|c|}
\hline Scales & $\begin{array}{c}\text { Contact with } \\
\text { Profession }\end{array}$ & $\begin{array}{l}\text { Intention to undertake } \\
\text { postgraduate research }\end{array}$ \\
\hline Learning Community & $0.19^{*}$ & $0.21^{*}$ \\
\hline Conceptualising Research Project & NS & $0.24^{\star *}$ \\
\hline Early Tasks & $0.16^{*}$ & $0.24^{\star *}$ \\
\hline Implementation of Research Tasks & $0.19^{*}$ & $0.20^{*}$ \\
\hline Presenting Results & NS & $0.26^{\star *}$ \\
\hline
\end{tabular}

\section{Table 5: Significant correlations with Contact with Profession and Intention to undertake postgraduate research}

The collection of data at a student's internship school is encouraged to make the TRP more meaningful and applicable to the practice of teaching. In this sense, the preservice training research project is more explicitly linked with the professional community of teachers rather than the academic community, particularly in the Implementation phase of the project. Nonetheless, there is some indication that a positive professional connection relates to a stronger academic connection.

\section{Intention to continue with postgraduate studies}

Of the 159 students surveyed, most reported that they did not anticipate that they would go on to postgraduate research. Five per cent (9 students) indicated that "yes" they did intend to continue. A further 30\% reported they were unsure. For this large group of students a positive experience in their TRP might "tip the balance" in favour of some of them eventually proceeding to undertake postgraduate research.

Reference to the final column of Table 5 indicates that feeling more connected to the learning community and confident in undertaking research tasks were related to 
intention to undertake postgraduate studies. Recalling that it was also the case that students who met more often with their supervisor were more likely to want to continue through to postgraduate study ( $r=0.17$ shown in Table 4 ), the links between supervision, confidence and intentions for research demonstrates the importance of the supervisor in the process of research, even a minor research project in a professional field.

The intention to continue on to postgraduate studies was also positively linked with students being more confident in carrying out research tasks identified in the Research Self Efficacy Scales. These correlation coefficients tended to be higher than other relationships found, ranging from 0.20 for Implementation of research tasks to 0.26 for Presenting Results. While it makes sense that those students who are more confident in carrying out research tasks are more likely to have an intention to carry on to higher degree research, only a very small percentage of these students are planning to do so at this point. This suggests a greater emphasis on research career paths, scholarships and a program to identify those who are capable of continuing could be fruitful.

The group of pre-service teachers who are unsure about continuing onto postgraduate study $(30 \%)$ are of particular interest. Members of this group are still open to the notion of continuing their study, and at the very least are teachers who may continue research in the professional context with some support or encouragement. Can we identify any factors which would influence their decision as to whether they will continue on to further study? By comparing the means of the "yes", "unsure" and "no" groups, it was found that for three of the research self-efficacy scales the mean of the unsure group was significantly closer to the no group than to the small yes group. This indicates that pre-service teacher confidence in their ability to carry out the tasks involved in research, in particular during the conception, implementation and presenting results stages, is related to whether they intend to continue. By increasing their confidence in carrying out research tasks particularly at the beginning of their research project, perhaps we can directly influence their intention to continue to research in the future.

\section{Research Orientation: Some Indicators About the Journey}

Research orientation is obtained through a plot drawn by the respondent on a set grid with time on the horizontal axis and positive to negative disposition on the vertical axis. The plot consists of various labelled and quantifiable spatial "points" on the student's research journey, using a graphic framework modified from that developed initially by Holbrook (1998) to identify futures orientation and the nature and density of futures imaging. It is used to complement the research self-efficacy scale, by adding a unique perspective on what the student feels about the journey (the highs and lows) 
and the tasks along the way. In addition, because the student was at most only a third of the way through the journey, it calls on them to project into the future, which also gives some indication of what tasks they think they yet have to complete ${ }^{1}$. So it captures positive and negative orientation to process.

Of the 159 respondents, 54 (34\%) completed this last item on the questionnaire. It may have been that the survey was too long, but response rates were higher in other disciplines surveyed for the larger study. Students in the early stages of a busy and challenging period of time, with many new experiences and information to digest may have been too overwhelmed to try and envisage the project to the end of semester. This may suggest a sub-group with particular characteristics elected to complete this section of the questionnaire. The different shapes of the plots that were recorded, however, suggest that they did differ in their dispositions towards the research project.

\section{An illustration of a journey of a pre-service teacher}

The Pre-Service Teacher research journey illustrated in Figure 1 was a female student studying full time in her fourth year of a Bachelor of Education (Science) degree. She was an Australian student aged between 25 and 34 years of age. She was unsure about whether she would undertake a postgraduate research degree in the future.

She had a male supervisor and was unsure as to whether he had any expertise in her topic of research. She met with him when required and had access to a computer lab for her research. She had freedom in her choice of topic. Her main project methods were: quantitative; statistical; and document analysis.

The research journey began, pessimistically, in the negative disposition range which became even more negative when it came to choosing a topic. In the open-ended section of the questionnaire this student commented that choosing the topic for her research project was difficult and there was little guidance about which direction to go in. When she did choose her topic, she was asked by her supervisor why she made that choice. When she said it was because she was interested and curious, her supervisor laughed and said that she "was a rarity - most research is done on the amount of literature available". Her journey continued to a high point when she decided on a topic and found literature for her project. It then dropped to a low when the student had a due date for submission, also indicating that she had other assignments due as well. This illustrates the level of coursework that is expected of the students in fourth year in addition to completing their TRP and internship.

In terms of predicting the journey, the student did not identify any tasks that would be required. This is reflected in her Research Self Efficacy Measure where she was only a little confident about Conceptualising (4.0), Early Tasks (4.0) and Presenting 
Results (4.0) and was not very confident about Implementing (3.0) the research tasks. In particular, even though she identified the literature as a high on her journey plot, she was not confident about generating researchable questions and with tasks related to the literature review. She did predict, however, that she will end on a high point by passing her TRP when it has been handed in. The fact that data collection, analysis and writing up were essentially collapsed into one component (essentially negative) may suggest that she had not identified the need for a clear plan of attack, or may indeed not have had any particular plan or understanding of how a project is operationalised.

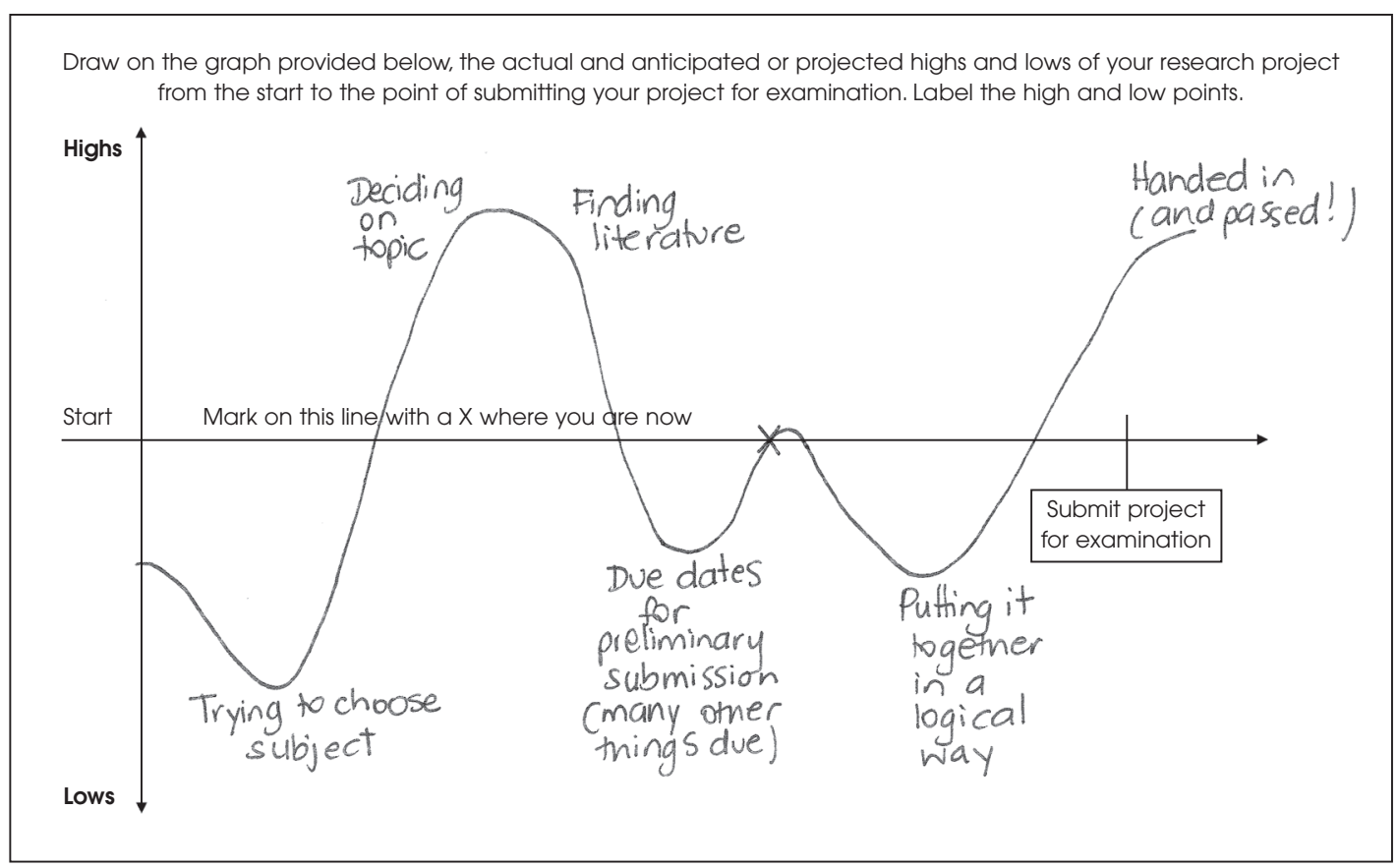

Figure 1: TRP Journey Plot (ID 20)

In general, the journey plot shows how the students see their progress to date and what they anticipate for the remainder of their research journey. While the plot is used as a qualitative measure to provide richness and context to the quantitative data obtained through the questionnaire the information is also quantifiable. Some elements of this are presented below.

If the focus is start and finish points it transpires there are nine main types of Journey Plots (see Table 6). Only 7\% of students who completed the Research Journey Plot started the journey with a positive disposition. Most students started their journey with a neutral (51\%) or a negative (42\%) disposition. 


\begin{tabular}{|c|c|c|}
\hline Type of Plot & Frequency & Percent \\
\hline Neutral start, Positive finish & 16 & 27 \\
\hline Neutral start, Neutral finish & 12 & 20 \\
\hline Neutral start, Negative finish & 2 & 3 \\
\hline Negative start, Positive finish & 16 & 27 \\
\hline Negative start, Neutral finish & 3 & 5 \\
\hline Negative start, Negative finish & 6 & 10 \\
\hline Positive start, Positive finish & 3 & 5 \\
\hline Positive start, Neutral finish & 1 & 2 \\
\hline Positive start, Negative finish & 0 & 0 \\
\hline Total & 59 & 100 \\
\hline
\end{tabular}

Table 6: Research Journey - Summary of plot positions at start and finish

A positive start to the journey is measured by the height of the starting point on the disposition (vertical) axis of the plot. In relative terms, those who had a more positive start to the research journey were more likely to be confident in "Conceptualising their research project" and "Implementing the research tasks" for their project (Table 7), including specific tasks such as generating researchable questions, brainstorming ideas in the literature and following ethical principles of research. They also experienced a positive research environment, including access to adequate library resources, databases and access to study areas.

\begin{tabular}{|c|c|}
\hline Scales & Start to Research Journey \\
\hline Conceptualising Research Project & $0.29^{*}$ \\
\hline Implementation of Research Tasks & $0.30^{*}$ \\
\hline Research Support & $0.29^{*}$ \\
\hline \multicolumn{2}{|c|}{ * Correlations significant at the 0.05 level (2-tailed) }
\end{tabular}

Table 7 Significant correlation with a Positive Start to the Research Journey

Providing students with a high level of research support is one way that a Faculty can create the best positive start for students beginning their research project. Those who had a perception that they were provided with a high level of support and were confident about the early research tasks involved in their project showed a positive visual representation of their journey.

While each journey plot is highly individual the grid allows comparison in key areas, such as start and finish positions, the nature of the items labelled, number of positive and negative peaks and overall pattern of peaks. By determining the mean height and number of peaks (positive and negative) it is possible to visualize the average journey (see Figure 2). On average students start with a poor disposition (Time 1), move to a 
lower position (Time 2), then to high and low alternately (Times 3 to 7 ) and finish on a very high note (Time 8). There is almost a complete balance of positive and negative points, tending towards the positive. This is very encouraging for both students and staff, particularly in the balance of the ups and downs. One can expect by looking at this mean plot, that even if you are experiencing a very low point on your research journey, that a positive is just around the corner!

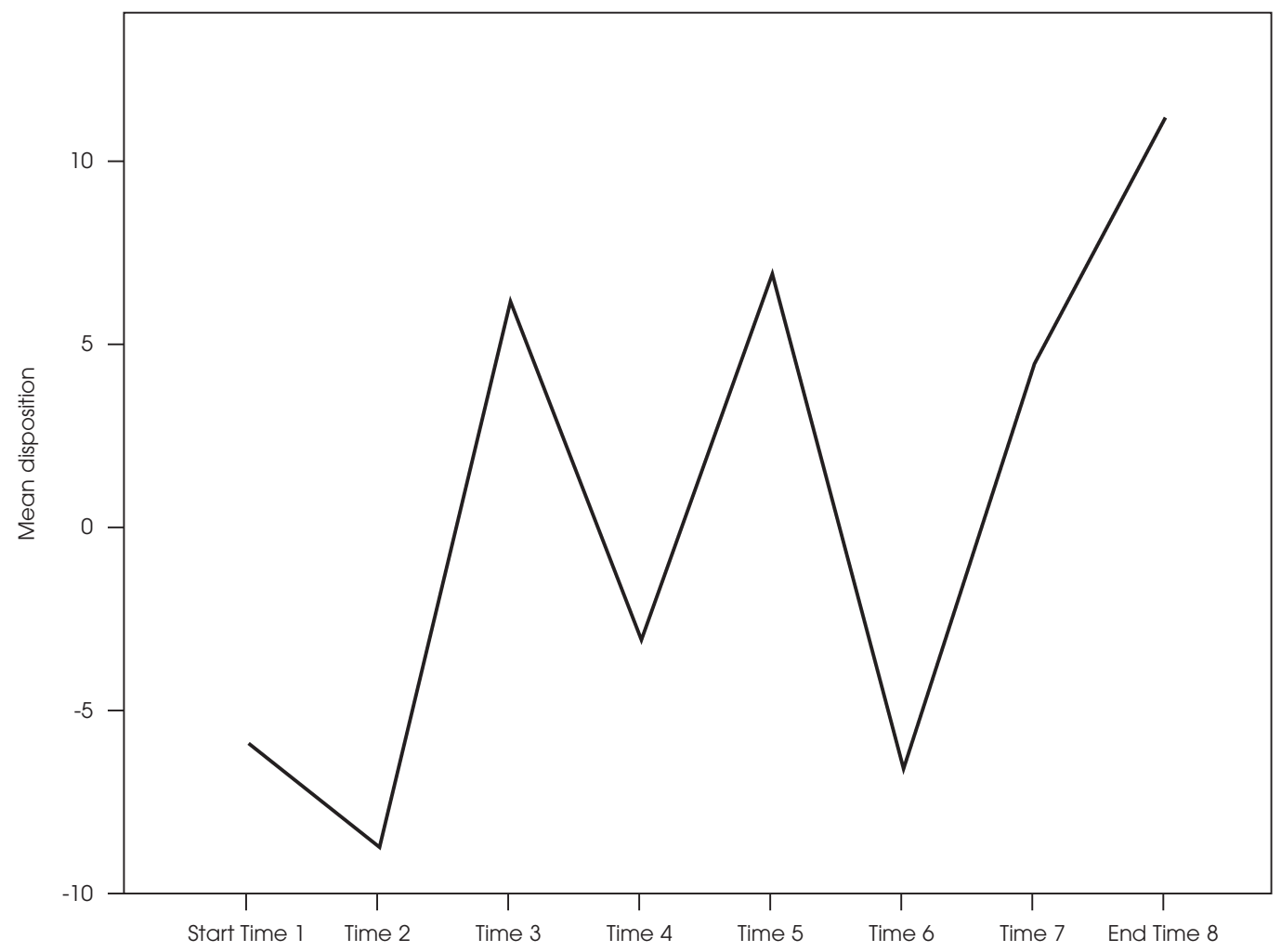

Figure 2: Mean Research Journey Plot

In terms of the research tasks, selection of the research topic was the main area of concern, comprising $50 \%$ of all comments for the first peak, with $70 \%$ being negative. Comments included "choosing a topic" (Education Student 136) and "trouble coming up with a research topic" (Education Student 58). Given that the majority of students felt the strain of developing their topic, this is not a surprising finding. However, more introductory training could be directed towards developing the topic, or there could be more direct influence by supervisors on limiting the choices of topic. Of the comments for Time 2, 20\% constituted a "personal reaction" to or realization about doing the project, and $85 \%$ of these were negative. Comments included: "realise how much of a hassle TRP will be" (Education Student 28) and "didn't want to do it" (Education Student 42). Clearly the conceptualization of the research project is a problem phase for which supervisors can prepare. 


\section{"Fragility"}

In the introduction to the paper questions were raised as to the fragility of the connection between early exposure to research activity and interest in research. In particular, the aims of a teacher research project are to build within professional practice the inclination to draw upon research findings when making educational decisions. It goes without saying that it is important to provide positive experiences of research.

Comments made by respondents in the open-ended section of the questionnaire illustrate the fragility of the connection. They were asked to contribute any additional information about their experience of fourth year, their research project or whether they would continue with postgraduate research studies in the future. Some 25\% responded. The responses were grouped into three main categories: the fourth year program (50\%); the research project (40\%); and the intention to continue on to postgraduate research (10\%). Most comments made were negative (90\%) and mainly in relation to fourth year and the research project.

There was an overwhelming concern by respondents about heavy workload in fourth year. They comprised $85 \%$ of the negative comments made about the fourth year program.

Some comments were reflective or advisory:

At a time when our confidence should be being built up to prepare us for going out into the teaching profession, many students have their confidence demoralised due to unreasonable workload commitments and only ever negative feedback and comment. (Education student 77)

The amount of pressure we have had this year was so ridiculous that I'm almost dreading being given a job. I feel overwhelmed. (Education student 86)

A few suggested extreme disaffection:

For three years we cruise along with mediocre subjects, then we're hit with an overload of work. I am close to a breakdown. (Education student 113)

Fourth year has been a nightmare, has made me hate being here and I can't wait to finish even more. Our workload has been unrealistic, I think, in terms of producing quality work. (Education student 154) 
Other comments in relation to the fourth year program related to: support; consistency; and self doubt.

All of the comments made about the research project were negative in tone and sought more input.

\section{Lack of support}

We're not given enough help; they assume we know what we're doing. (Education student 39)

Initial support was poor and I felt lost and unable to find my way. (Education student 53)

The TRP advisors need to get together. One advisor should not contradict another as in my case. This makes it TERRIBLY hard. (Education student 80)

\section{Lack of training}

Very little/no direction in regards to TRP. Told to buy the textbook and that's it. (Education student 55)

Need more direct/explicit teaching of research methods and procedures. (Education student 114)

\section{Relevance and time pressures}

We have enough work on without worrying about a meaningless TRP the only reason I will finish it is to get a degree. I will never use it again. (Education student 107)

The research project should not be invading our time on internship. (Education student 131)

The comments of the $25 \%$ who responded provide some insight into the intensity of the experience. There were no significant correlations between those who made comments and other elements of the questionnaire aspects. Even if we assume that those who did not comment were positive, there is reason to be concerned that the workload (including the pressure of a research project) gives rise to such a negative view of the experience by a sizeable group. There can be no doubt, given the evidence presented, that the research project requirements in a busy and pressured year led to a significant level of concern and anger. 


\section{Conclusion}

Most of the pre-service teachers in the study (65\%) reported that they did not anticipate they would undertake future postgraduate study, 30\% were not sure and 5\% were sure they would go on. On the whole this could be taken as a positive finding insofar as about one third were at least open to undertaking postgraduate study in the future. It is worrying, however, that more than twice as many were closed to the notion, especially so when combined with the fact they did not want to be connected to the academic community. Those who met most frequently with their supervisor and showed higher research self-efficacy were most likely to want to undertake postgraduate study. Moreover, if they had experienced a strong connection with teachers in the early phases of their project they were more "connected to the academic community".

As a cohort there was a general belief that they could handle the skills required in the TRP, although there was evidence that many students experienced frustration in developing research questions and undertaking a literature review within a restricted time frame. This may have been exacerbated by the compressed delivery of the program, the reliance given to on-line support to teach students research skills, and the lack of contact with the academic supervisors. Typically students started off shakily but were optimistic about the outcome. The findings raise the question of how best to support and scaffold students in their early research endeavours so that they feel they can perceive positive progress in the research rather than feel alienated by the effort required in a busy program.

A new direction in the delivery of the Teacher Research Project is required to engage our pre-service teachers. Teachers are increasingly facing the pressure to display ongoing professionalism, and to base their practice on a body of professional knowledge. The aim of this course is for teachers to develop a template for professional learning that they can use after they leave university as they map a career for themselves. One of the concerns students faced, which was particularly identified in their personal journeys, was their choice of topic. A focus for improving the course may be to trial allocating a more specific topic for the Teacher Research Project, based more on reflective practice or action research linked to their teaching internship. This greater focus may make the project more relevant in the workplace. As found in this study, it is also important to develop research groups for peer support and set up more regular meetings with the supervisors to enhance the experience for students. Students could join a reflective group, led by a supervisor or mentor, meeting on a more frequent basis in the style of a tutorial. This would provide more scaffolding and support to pre-service teachers in an already hectic final year. 
There can be little doubt we need education professionals who want to undertake postgraduate degrees and engage in research that benefits and transforms society. It would appear that an undergraduate research project linked to internship placement does develop research awareness, but not all of this is positive. Students for the most part took away a very negative research experience as a result of the Teacher Research Project. What effect will this have on their desire to continue on to postgraduate studies or to use research to inform their practice? It appears that for most new teachers the desire to undertake any further study, let alone research study, is simply absent. This is an interesting finding given that teachers draw on research to inform their practice (McMeniman et al., 2000) and that evidence-based practice is gaining momentum in schools (James, 2006). It bears considering that more effort should be put into identifying and supporting those undergraduates who are strongly motivated to undertake postgraduate study or research in the future. It is this group, we know from other research, who will very likely become the leaders in research and engage in and model evidence-based practice (Holbrook et al., 2000, p. 29).

\section{Endnote}

1 The plots yield data for further scale development such as positive and negative orientation to research, research imaging and research trajectory and these are being developed in relation to the larger study.

\section{References}

Anderson, R. (2004, November). A responsive evaluation into a small group approach to the supervision of BEd (Hons) students. Paper presented at the AARE Conference, Melbourne. Retrieved June 5, 2006, from http://www.aare.edu.au/confpap.htm

Burgio-Ficca, C. (2001). The contribution of the higher education sector to Australian research and development. Australian Journal of Education, 45(3), 263-28.

Davis, H., Evans, T., \& Hickey, C. (2006). A knowledge-based economy landscape: Implications for tertiary education and research training in Australia. Journal of Higher Education Policy and Management, 28(3), 231-244.

Diezmann, C. M. (2005). Growing scholarly teachers and educational researchers: A curriculum for a research pathway in pre-service teacher education. Asia-Pacific Journal of Teacher Education, 33(2), 181-193.

Figgis, J., Zubrick, A., Butorac, A., \& Alderson, A. (2000). Backtracking practice and policies to research. In DETYA Higher Education Division (Ed.), The impact of educational research. Canberra: DETYA.

Fitzsimmons, P., Anderson, R., McKenzie, B., \& Chen, H. (2003, October). An eye on the prize: Fourth year Honours students, thesis writing and the group supervision 
process. Paper presented at the AARE Mini-conference, Newcastle. Retrieved June 5, 2006, from http://www.aare.edu.au/conf03nc/fi03018z.pdf

Forester, M., Kahn, J., \& Hesson-McInnes, M. (2004). Factor Structures of three measures of research self-efficacy. Journal of Career Assessment, 12(1), 3-16.

Garcia-Duncan, T., \& McKeachie, W. (2005). The making of the Motivated Strategies for Learning questionnaire. Educational Psychologist, 4O(2), 117-128.

Hawes, C., \& Flanagan, A. (2000). The experience of Honours at Flinders University: Perspectives of students and coordinators. In M. Kiley \& G. Mullins (Eds.), Quality in postgraduate research: Making ends meet. Adelaide: University of Adelaide, Advisory Centre for University Education.

Holbrook, A. (1998). The futures orientation of teachers. In D. Hicks \& R. Slaughter (Eds.), World yearbook of education: Futures of education. London: Kogan Page.

Holbrook A., Ainley J., Bourke S., Owen J., McKenzie P., Misson, S., et al. (2000). Mapping educational research and its impact on Australian schools. In DETYA Higher Education Division (Ed.), The Impact of Educational Research. Canberra: DETYA.

Holmberg, L. (2006). Coach, consultant or mother: Supervisors' views on quality in the supervision of bachelor theses. Quality in Higher Education, 12(2), 207-216.

James, M. (2006). Balancing rigour and responsiveness in a shifting context: Meeting the challenges of educational research. Research Papers in Education, 21(4), 365-380.

Johnson, S., \& Broda, J. (1996). Supporting educational researchers of the future. Educational Review, 48(3), 269-281.

Kaestle, C. (1993). The awful reputation of education research. Educational Researcher, 22(1), 23-31.

Lovitts, B. (2005). Being a good course-taker is not enough: A theoretical perspective on the transition to independent research. Studies in Higher Education, 30(2), 137154.

McMeniman, M., Cumming, J., Wilson, J., Stevenson, J., \& Sim, C. (2000).Teacher knowledge in action. In DETYA Higher Education Division (Ed.), The Impact of Educational Research. Canberra: DETYA.

Pintrich, P., \& Schunk, D. (1996). Motivation in education. Theory, research, and applications. New Jersey: Prentice Hall.

Reis-Jorge, J. (2005). Developing teacher's knowledge and skills as researchers: a conceptual framework. Asia-Pacific Journal of Teacher Education, 33(3), 303-319.

Robertson, J., \& Blacker, G. (2006). Students' experiences of learning in a research environment. Higher Education Research and Development, 25(3), 215-229.

Waite, S., \& Davis, B. (2006). Developing undergraduate research skills in a faculty of education: Motivation through collaboration. Higher Education Research \& Development, 25(4), 403-419. 